\title{
Chondrocalcinosis: Sonographic Study of the Knee
}

\author{
G.COARI, A. IAGNOCCO,A. ZOPPINI
}

\begin{abstract}
Summary Sonography of the knee was performed in 28 patients with chondrocalcinosis and in 46 normal subjects. In each joint the authors examined synovial membrane, articular cartilage of femoral condyles, synovial fluid and menisci; they also searched for Baker's cysts. A significant thickening of synovial membrane was present. In 43 joints sonography showed linear hyperechoic images within condylar cartilage; they were parallel to bone surface and were interpreted as calcifications because of the coincidence with radiographic images. A significant thinning of articular cartilage was also found. Sonography of the knee is a useful method of examination for the evaluation of articular changes in chondrocalcinosis.
\end{abstract}

Key words Chondrocalcinosis, Sonography, Knee

\section{INTRODUCTION}

Sonography (SN) has not yet been applied (1-11) to the study of articular changes caused by chondrocalcinosis (CC). For this reason the authors examined articular structures of the knee in patients with $\mathrm{CC}$ and evaluated the appearance of calcifications within articular cartilage and menisci.

\section{MATERIALS AND METHODS}

The knees of 28 patients (14 males and 14 females) with $\mathrm{CC}$ were examined; their mean age was of 58.8 years (range 32-81). All subjects were hospitalized in the Rheumatology Department of Rome University «La Sapienza». In all patients anteroposterior and lateral radiographs of the knee had been performed. The diagnosis of CC was made according to criteria reported by McCarty (2). Cartilaginous calcifications of femoral condyles were verified by radiological examination ( 25 subjects). Birefrangent crystals were found in synovial fluid of 23 patients. Meniscal calcifications checked on radiographs were present in 41 knees (73.2\%). The mean illness duration was of 6.8 years (range 2-9).

The diagnosis of CC was definite in 18 cases and probable in 10 . In the 3 patients with negative radiographs the crystals were found in the synovial fluid (Table I).

$\mathrm{SN}$ was performed using a $7.5 \mathrm{MHz}$ linear probe. Synovial membrane, articular cartilage of femoral condyles,

Rheumatology Department University "La Sapienza", Rome, Italy synovial fluid and the calf were studied. Synovial membrane was examined in lateral and supra-patellar compartments; its thickness was measured and villi and septa were searched for.

The thickness of articular cartilage was measured. Changes of the two surfaces (cartilage-bone and cartilage-soft tissues) and scattered echoes within the translucent band were detected. When the presence of effusion prevented the correct evaluation of the cartilage, measurements were done after arthrocentesis; in 2 knees it was not possible to completely evacuate synovial fluid and measurement was not reliable. Using Aisen's technique $(12,13)$, measurements were taken at 3 specified points (A, B and C) just above the superior margin of the patella and then they were repeated $2 \mathrm{~cm}$ above it. Afterwards the mean value of each set of results was calculated. The quality of cartilage surfaces was examined classifying them as regular or irregular. Moreover hyperechoic images, parallel to the surfaces, were searched for. They were examined both in longitudinal and transverse scannings along femoral condyles. They were classified as punctiform when their length was less than $1.5 \mathrm{~mm}$ and linear when it was longer. They were interpreted as cartilaginous calcifications due to the deposition of calcium pyrophosphate, comparison of radiographs having shown the coincidence of the two findings (Fig. 1).

Effusion was searched for and its sonographic aspect was evaluated indicating whether it appeared anechoic or if it had scattered echoes. In the calf, Baker's cysts were searched for and their volume was calculated. Meniscal calcifications were also detected. 
Table I: Changes in the joints examined

\begin{tabular}{lcc}
\hline & $\begin{array}{c}\text { No. of knees } \\
56\end{array}$ & $\%$ \\
\hline $\begin{array}{l}\text { Radiographic changes } \\
\text { present }\end{array}$ & 50 & $89.3 \%$ \\
$\quad$ absent & 6 & $10.7 \%$ \\
\hline $\begin{array}{l}\text { Pyrophosphate crystals } \\
\text { in synovial fluid } \\
\quad \text { examination } \\
\text { present } \\
\text { absent }\end{array}$ & 46 & \\
$\begin{array}{l}\text { Symptoms } \\
\text { present } \\
\text { absent }\end{array}$ & 46 & $100 \%$ \\
\hline
\end{tabular}

Incidence of diagnostic criteria for $\mathrm{CC}$ in the joints examined.

Results were compared with those obtained by examination of 46 healthy subjects of the same mean age. "Chisquare" test and Student's t-test were used for statistical analysis.

\section{RESULTS}

Table II reports the results obtained by the examination of the knees of patients with CC and of healthy subjects. The mean thickness of synovial membrane was $5.3 \mathrm{~mm}$ (range $3-11 \mathrm{~mm}$ ); the higher values were $11 \mathrm{~mm}$ in one case and $9 \mathrm{~mm}$ in two cases. Synovial villi were present in $10.7 \%$ (6 knees) of joints and septa were never found. Articular cartilage appeared thinner in patients with CC as compared to normal subjects; there were significant differences: in $\mathrm{A}$ its mean thickness was 0.96 $\mathrm{mm}$, in B it was $1.48 \mathrm{~mm}$ and in C it was $1.16 \mathrm{~mm}$.

The surfaces were irregular in 43 knees (76.8\%). In 43 joints $(76.8 \%)$ hyperechoic images, parallel to the surfaces were present. They were linear in 26 knees $(60.5 \%)$ and punctiform in 30 joints (69.8\%); both findings were present in 13 cases $(30.2 \%)$. Statistical analysis of the results obtained did not show any significant differences between radiographic and sonographic findings of cartilaginous calcifications.

In 3 joints (5.4\%) calcifications within the posterior horn of medial meniscus were visible. Significant differences were present between radiographic and sonographic findings (Table III).

Table II: Survey and results

\begin{tabular}{|c|c|c|c|}
\hline & Subjects with CC & Normal subjects & Statistical significance \\
\hline No. of subjects & 28 & 46 & \\
\hline males & 14 & 21 & \\
\hline females & 14 & 25 & \\
\hline Mean age & $58.5(32-81)$ & $53.1(42-74)$ & \\
\hline Mean illness duration & $6.8(2-9)$ & - & \\
\hline No. of knees & 56 & 92 & \\
\hline \multicolumn{4}{|l|}{ Synovial membrane: } \\
\hline Thickness $\mathrm{mm}$ & $5.3(3-11)$ & $2.9(2-5)$ & $\mathrm{p}<0.001$ \\
\hline Presence of villi & $6(10.7 \%)$ & 0 & \\
\hline Presence of septa & 0 & 0 & \\
\hline \multicolumn{4}{|l|}{ Condylar cartilage: } \\
\hline Thickness at A mm & 0.96 & 1.91 & $\mathrm{p}<0.0005$ \\
\hline $\mathrm{B} \mathrm{mm}$ & 1.48 & 2.03 & $\mathrm{p}<0.001$ \\
\hline $\mathrm{C} \mathrm{mm}$ & 1.16 & 1.92 & $\mathrm{p}<0.001$ \\
\hline Aspect: regular & $13(23.2 \%)$ & $80(86.9 \%)$ & $\mathrm{p}<0.000 .001$ \\
\hline irregular & $43(76.8 \%)$ & $12(13.1 \%)$ & $\mathrm{p}<0.000 .001$ \\
\hline Calcifications: & $43(76.8 \%)$ & 0 & \\
\hline linear & $26(60.5 \%)$ & & \\
\hline punctiform & $30(69.8 \%)$ & & \\
\hline meniscal & $3(5.4 \%)$ & & \\
\hline \multirow{4}{*}{$\begin{array}{l}\text { anechoic } \\
\text { scattered echoes }\end{array}$} & $7(12.5 \%)$ & 0 & \\
\hline & $5(71.4 \%)$ & & \\
\hline & $2(28.6 \%)$ & & \\
\hline & $1(1.8 \%)$ & 0 & \\
\hline
\end{tabular}

Sonographic study of synovial membrane and articular cartilage of the knee showed significant differences between patients with $\mathrm{CC}$ and normal subjects. 
Table III: Presence of calcifications

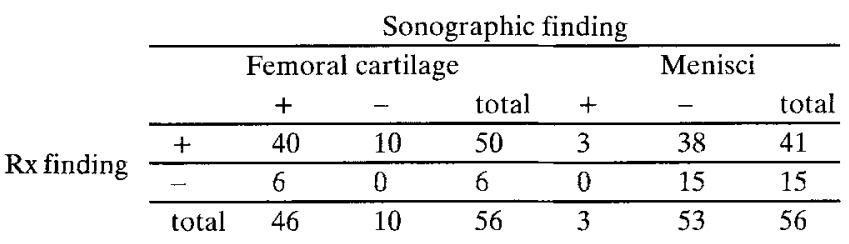

Correlation between cartilaginous and meniscal calcifications at radiographic and sonographic examinations.

Effusion was found in 7 knees (12.5\%); it was anechoic in 5 joints (71.4\%) and it had scattered echoes twice.

Only one Baker's cyst was found. Its volume was $37,2 \mathrm{ml}$, there were scattered echoes within it and appeared to be no connecting channel with the joint.

\section{CONCLUSIONS}

In CC changes of synovial membrane (thickening, synovial villi, effusion) were similar to those found in inflammatory diseases (14-17); those findings show that $\mathrm{CC}$ is a disease with inflammatory factors which often attack the $\mathrm{AC}$ with degenerative changes caused by old age of patients (18-19). Moreover synovial phlogosis may increase cartilaginous damage and it could justify the thinning of cartilage in $\mathrm{CC}$, which is similar to that of serious osteoarthritis. The typical finding of $\mathrm{CC}$ was the presence of hyperechoic, linear images within the cartilage, parallel to bone surface (Table III). They appeared both in longitudinal and transverse scannings and were found only in CC.

The high sensibility of radiography should not lead us to underestimate the importance of $\mathrm{SN}$ : in 3 patients without radiologic findings of the disease the diagnosis of CC was suspected by the sonographic demonstration of cartilaginous calcifications and it was confirmed by the examination of synovial fluid.

In the 46 normal subjects linear hyperechoic images were never present. Upon sonographic examination of cartilage the rare possibility of the appearance of artifacts simulating cartilaginous calcifications must be considered; for this reason the diagnosis of $\mathrm{CC}$ must always be confirmed. There were significant differences between the radiologic and sonographic indications of meniscal calcifications (Table III). This confirms that $\mathrm{SN}$ is not sensitive enough for a correct and complete study of menisci.

It must be acknowledged that $\mathrm{SN}$ is a useful imaging technique in the study of $\mathrm{CC}$ both for diagnosing and monitoring of articular damage and appraising the effects of possible therapy.

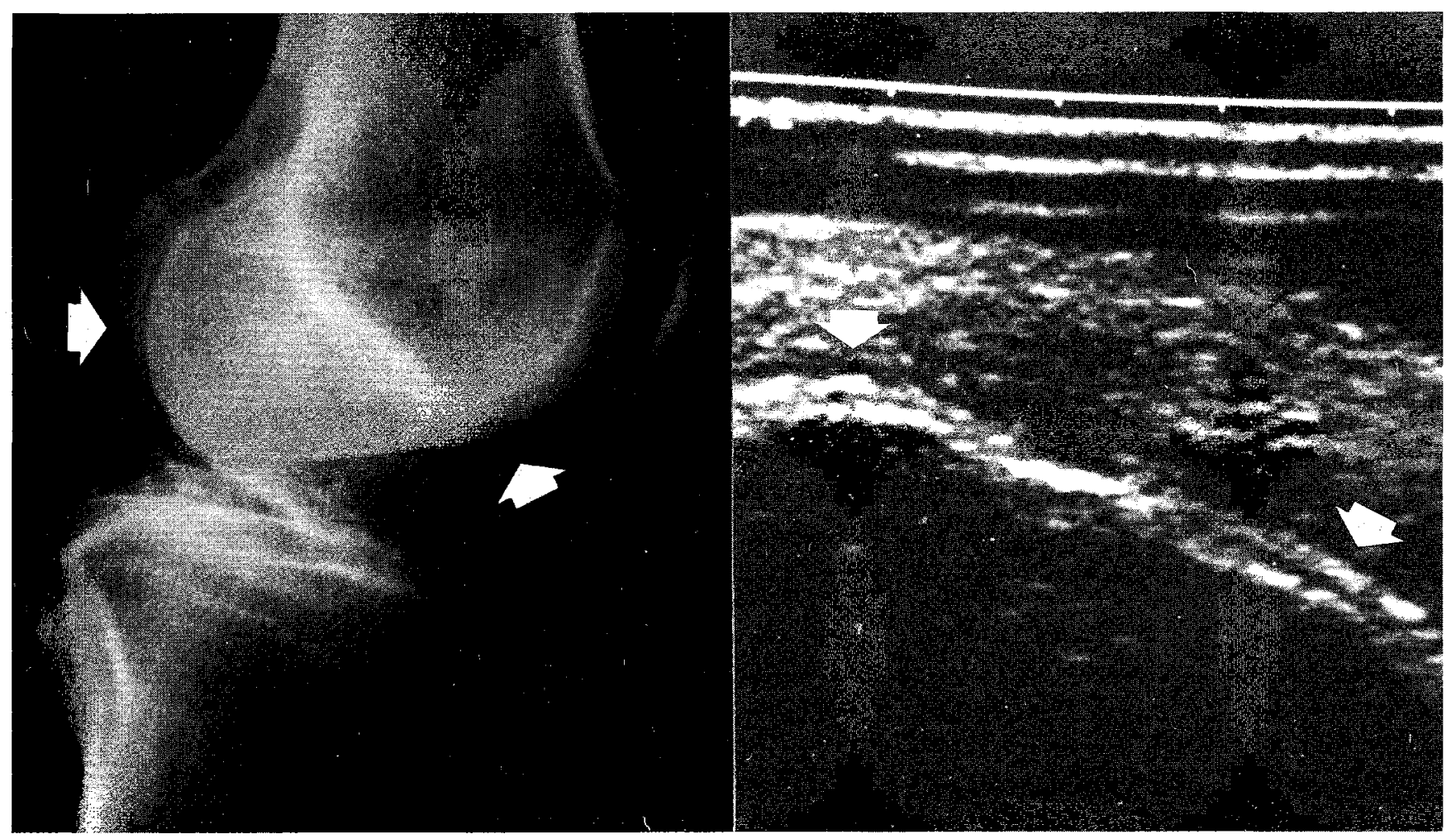

Fig. 1: Radiographic (a) and sonographic (b) findings of cartilaginous calcifications in CC. 


\section{REFERENCES}

1. Moskowitz, R.W. Diseases associated with the deposition of calcium pyrophosphate or hydroxyapatite. In: Textbook of Rheumatology, 4th ed., Eds.: Kelley, W.N., Harris, E.D., Ruddy, S., Sledge, C.B., Philadelphia, W.B. Saunders Company, 1993, 1337-1354

2. Ryan, L.M., McCarty, D.J. Calcium pyrophosphate crystal deposition disease; pseudogout; articular chondrocalcinosis. In: Arthritis and Allied Conditions, 12th ed., Eds.: McCarty, D.J., Koopman, W.J., Philadelphia, Lea and Febiger, 1993, 1835-1855

3. Terkeltaub, R.A. Pyrophosphate arthropathy. Rheumatology Review 1993, 2, 1-9.

4. McCarty, D.J. Calcium pyrophosphate dihydrate crystal deposition disease. Br J Rheum 1993, 32, 177-180.

5. Doherty, M., Dieppe, P., Watt, I. Pyrophosphate arthropathy: a prospective study. Br J Rheum 1993, 32, 189-196.

6. Regan, M., Clarke, K., Doherty, M. Pseudogout provoked by pregnancy. Br J Rheum 1993, 32, 245-247.

7. Fisseler-Eckhoff, A., Müller, K.M. Arthroscopy and chondrocalcinosis. Arthroscopy: The Journal of Arthroscopic and Related Surgery 1992, 8, 98-104.

8. Rothschild, B.M., Woods, R.J. Geographic distribution of calcium pyrophosphate (CPPD) deposition disease in pre-Columbian North America: independent validation of CPPD criteria. Clin Exp Rheumatol 1993, 11, 315-318.

9. Brandt, K.D., Schumacher, H.R. Jr. Osteoarthritis and crystal deposition diseases. Curr Opin Rheumatol 1993, 5, 483-486.

10. Ryan, L.M. Calcium pyrophosphate dihydrate deposition and other crystal deposition diseases. Curr Opin Rheumatol 1993, 5, 517521.

11. Buckwalter, K.A. Imaging in osteoarthritis and crystal deposition diseases. Curr Opin Rheumatol 1993, 5, 503-509.

12. Aisen, A.M., McCune, W.J., MacGuire, A., Carson, P.L., Silver, T.M., Jafry, Z.S., Martel, W. Sonographic evaluation of the cartilage of the knee. Radiology 1984, 153, 781-784.
13. McCune, W.J., Dedrick, D.M., Aisen, A.M., MacGuire, A. Sonographic evaluation of osteoarthritic femoral condylar cartilage. Clin Orthop 1990, 254, 230-235.

14. Kaufman, R.A., Twobin, R.B., Babcock, D.S., Crawford, A.H. Arthrosonography in the diagnosis of pigmented villonodular synovitis. Am J Radiol 1982, 132, 396-398.

15. Gagnerie, F., Taillan, B., Bruneton, J.N., Bonnard, J.M., Denis, F., Commandre, F, Euller-Ziegler, L., Ziegler, G. Three cases of pigmented villonodular synovitis of the knee. Fortschr Roentgenstr 1986, 145, 227-228.

16. Van Holsbeek, M., Van Holsbeek, K., Gevers, G., Marshal, G., Van Steen, A., Favril, A., Gielen, J., Dequeker, J., Baert, A. Staging and follow-up of rheumatoid arthritis of the knee. Comparison of sonography thermography and clinical assessment. J Ultrasound Med 1988, 7/10, 561-566.

17. Coari, G., Iagnocco, A. Studio ecografico del ginocchio nell'artropatia psoriasica. Simposio internazionale artropatia Psoriasica. Reggio Emilia. Book of Abstracts 1991, 161.

18. Iagnocco, A., Coari, G., Zoppini, A. Natural evolution of osteoarthritis: Sonographic study of the knee. 5th INWIN, Interscience World Conference on Inflammation, Antirheumatics Analgesics Immunomodulators. Geneva. Book of Abstracts 1993, 278.

19. Iagnocco, A., Coari, G., Zoppini, A. Sonographic evaluation of femoral condylar cartilage in osteoarthritis and rheumatoid arthritis. Scand J Rheumatol 1992, 21, 201-203.

Received: 21 March 1994

Revision-accepted: 28 December 1994

Correspondence to: Dr. A. Iagnocco,

Istituto di Reumatologia Università "La Sapienza"

Policlinico Umberto I

I-00161 Rome, ITALY 